\title{
ISLAM NUSANTARA; SEBUAH KAJIAN POST TRADISIONALISME DAN NEO MODERNISME
}

\author{
Abdul Basid \\ PhD Candidate And Researches \\ University Of The Holy Qur'an And Islamic Sciences, Sudan \\ E-mail: quraishbasid@gmail.com
}

\begin{abstract}
Islamic Nusantara is not new religion, not just the new thought. Islamic Nusantara is the approach resourches of transcendent scientific which have religion character and then mergered by humanism sciences resourches which have humanism character. Islamic nusantara culture hoped became scientific resouches and culture inheritance which resourched form local wisdom Indonesian people that mixed between transcendent approach and local wisdom aprroach . Islamic Nusantara not just born from tradition, that the tradition became new power which rested on the power of society and constructed by sciences and knowledge and became morality power as the first bollard. These paper will explain the thought of The Islamic Nusantara as post traditionalism and neo modernism studied.
\end{abstract}

Keywords: Islamic, Nusantara, Post Traditionalism, Neo Modernism 


\section{Pendahuluan}

Islam Nusantara bukan agama baru, bukan juga merupakan paham baru. Islam Nusantara merupakan sebuah pendekatan Sumber Ilmu pengetahuan Transenden yang bersifat ilahiah (Agama) kemudian dipadukan dengan sumber Ilmu kemasyarakatan yang bersifat kemanusiaan. Dalam segi Sumber Ilmu, Islam adalah merupakan agama ilahiah yang bersifat transenden dan kebenarannya adalah mutlak. Akan tetapi Islam memberikan ruang kepada manusia untuk mendapatkan kebenaran mutlak tidak hanya saja memahami teks akan tetapi harus memahami behind of text atau yang lebih kita kenal dengan kontektualitas dari sebuah teks. Adalah sebuah keniscayaan mengapa teks itu muncul, apa latar belakangnya, apa sebab konteks sosio-kulturalnya dan apa guna dan manfaatnya. Pemahaman tentang tekstualitas akan mempengaruhi cara pandng dan pemikiran serta aksiologi dari teks itu sendiri. Islam Nusantara adalah sebuah gagasan untuk mengkompromikan agama dan budaya. Islam Nusantara juga tidak membenarkan adanya suatu tradisi yang bertentangan denga syariat Islam.

Nasr Hamid Abu Zaid mengemukakan tentang teks dan konteks

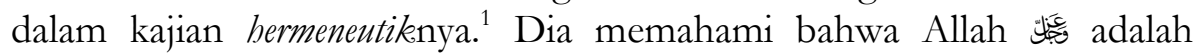
Creator Of Text, pemilik ototitas dalam sebuah teks dan konteks, kemudian dalam menyampaikan wahyu Allah yang notabene merupakan Transformator of Text, kita juga memahami bahwa dia tidak mungkin tidak menyampaikan teks itu, karena kita mengenal dengan konsepnya bahwa tidak akan pernah bermaksiat (menganulir text) dan menjalankan apa yang telah diperintah padanya. Kemudian Nabi Muhammad adalah tidak hanya Transformator of Text tetapi juga beliau adalah The Reader of Text. Berbicara tentang reader of Text maka yang dipahami adalah bagaimana membumikan teks, mengkontekstualitaskan teks, menghidupkan teks dan tidak hanya terjebak pada teks-teks demi kepentingan belaka.

\section{Islam Nusantara - Tradisionalis - Post Tradisionalis}

Gagasan dan metodologi Islam Nusantara merupakan aksiologi of text yang dikumandangkan oleh walisongo sebagai hasil dialektika antara teks dengan realitas budaya setempat. Demikian sejatinya Islam Nusantara bukan hanya gagasan yang tiba-tiba muncul akan tetapi ontologis dan epistemologis Islam Nusantara sudah membumi meskipun tidak

\footnotetext{
1 Nasr Hamid Abu Zaid, Hermeneutika Inklusif, (Jogykarta: Jaya Pustaka, 2001), 89.
} 
memakai istilah tersebut. ${ }^{2}$ Sense of Islam Nusantara sudah hadir sebelum istilah itu dibumikan, yaitu karena yang ada di alam Nusantara ini bukan hanya Alam saja akan tetapi ada manusia yang harus dimanusiakan kemanusiannya.

Kajian budaya Islam Nusantara diharapkan menjadi dasar Ilmu pengetahuan dan warisan budaya yang bersumber dari kearifan lokal masyarakat Indonesia yang menggabungkan antara sumber transenden dengan local wisdom humanity. Dalam menghadapi dunia global semestinya jangan sampai kehilangan akar kebudayaan bangsa. Karena yang paling penting adalah mengembangkan pengetahuan tetap bercorak humanisme yang digali dari nilai-nilai masyarakat Indonesia. ${ }^{3}$

Yang menarik dalam pemikiran ini adalah penulis berusaha menyajikan berbagai pandangan, yang dimulai mengenai Islam Nusantara sebagai kawasan dan perspektifnya, kemudian penulis menyajikan bagaimana korelasi antara Islam Nusantara sebagai gerakan kultural, Islam Nusantara, dan Tradisi dalam sejarah muslimin. Selanjutnya penulis menjelaskan siapa saja para founding father of islam nusantara. Yang tidak kalah penting adalah bagaimana peninggalan para founding father yang telah membumikan Islam Nusantara dengan berbagai manuskrip-manuskrip yang mungkin pada dasawarsa ini para peneliti muda sedang menilik dan berusaha mengeskplor hasil maha karya mereka karena ini adalah peninggalan yang harus selalu dipertahankan keeksistensisannya baik secara kultural maupun struktural.

Islam Nusantara bisa saja diperselisihkan. Terlepas setuju atau tidak setuju dengan istilah tersebut, penulis memandang pada Islam sebagai substansi ajaran. Islam pertama turun di Makkah lalu tersebar ke Madinah dan kedaerah-daerah lainnya, seperti Yaman, Mesir, Irak, India, Pakistan, Indonesia dan seluruh dunia. Islam bertemu dengan budaya setempat. Pada mulanya Islam di Makkah bertemu dengan budaya Makkah dan sekitarnya. Akulturasi budaya dan agama; Pertama, adakalanya Islam menolak budaya setempat -seperti halnya budaya perkawinan di Makkah. Kali itu ada banyak cara menikah. Salah satunya, terlebih dahulu perempuan berhubungan seks secara bebas dengan sepuluh orang laki-laki, jika hamil perempuan bebas memilih salah satu dari mereka. Kedua, adakalanya Islam merevisi budaya yang telah ada,

2 Ahmad Baso, Islam Nusantara; Ijtihad Jenius dan Ijma' Ulama' Nusantara (Jakarta: Pustaka Afid, 2015), 77

3 KH Abdurrahman Wahid, Mengurai Hubungan Agama dan Negara, Jakarta: Erlangga, 1999), 91. 
misalnya sejak dahulu sebelum datang Islam orang Makkah sudah melakukan thawaf (mengelilingi Ka'bah). Namun, kaum perempuan ketika thawaf tanpa mengenakan busana. Alasan mereka karena harus suci, mengenakan busana bisa jadi tidak suci, maka mereka menghadap Tuhannya dengan apa adanya alias "telanjang" kemudian Islam datang tetap mentradisikan thawaf akan tetapi merevisinya dengan harus berpakaian suci dan bersih, serta berpakaian ihram bagi yang menjalankan haji dan umrah. Ketiga, Islam hadir menyetujui budaya dan tanpa merevisinya. Seperti budaya pakaian orang arab, yang laki-laki mengenakan jubah dan perempuan berjilbab -oleh Islam budaya ini diterima. Islam Nusantara bukanlah istilah baru, akan tidak lepas dan hanya berkutat pada istilah, lebih daripada itu yaitu sebuah substansi dari Islam. Dengan demikan, umat Islam akan lebih saling menerima, dan menjadikan perbedaan sebagai rahmat bukan laknat. ${ }^{4}$

Islam Nusantara bukan hanya Islam yang lahir dari tradisi, akan tetapi bisa menjadikan tradisi untuk sebuah kekuatan baru yang bertumpu pada kekuatan rakyat sipil dengan berbekal kontruksi pengetahuan dan ilmu pengetahuan dan menjadikan kekuatan moral sebagai tonggak utama. Sayyid Hossen Nasr, berpendapat dalam bukunya Traditional Islam In The Modern World, adalah gerakan kaum tradisionalis mereka sangat bertumpu pada semangat dan gerakan rohani yang dibawa oleh tasawuf, masyarakat diarahkan kepada revolusi rohani disandingkan dengan aspek syariat. Pemikiran Sayyid Hossein Nasr ini, formulasinya telah dicetuskan terlebih dahulu oleh Imam al-Ghazali, Imam al-Qushairi dan para pendahulunya. $^{5}$

Sejak tahun 1970-an, muncul corak intelektualitas baru di kalangan NU yang antara lain dimotori oleh Abdurrahman Wahid (Gus Dur) dan Mahbub Junaidi. Corak baru tersebut terus berkembang di kalangan generasi berikutnya seperti Masdar F. Mas'oedi, Ulil Absshar Abdallah, Abdul Mun'im Dz, Ahmad Baso dan sebagainya. ${ }^{6}$ Pengembangan wacana di kalangan mereka sampai menyentuh pada persoalan-persoalan yang tidak lazim di kalangan NU, karena telah melampaui batas tradisionalisme yang sebelumnya menjadi stereotype mereka. Gagasan-

\footnotetext{
${ }^{4}$ Zuhdi, Nasionalisme NU,( Semarang: Aneka Ilmu, 2007), 51.

${ }^{5}$ Stephen Schawts, Moderatism vs Fundamentalisme, (Jakarata: LibForAll, 2008), 44.

${ }^{6}$ Corak intelektualitas baru di kalangan NU mengalami perkembangan secara relatif massif di kalangan PMII dan kelompok kajian yang dibangun oleh komunitas PMII di luar struktur organisasi. Begitu juga dengan munculnya lembaga-lembaga berlatar belakang NU yang menjadi motor bertebarnya wacana seperti LKiS di Yogyakarta, eLSAD di Surabaya, Lakpesdam, P3M dan sebagainya.
} 
gagasan yang dilahirkan juga sangat liberal melampaui apa yang dilahirkan oleh kelompok modernis.

Anehnya, komunitas intelektual NU tersebut tidak mengambil inspirasi dari pemikir-pemikir modernis. Di kalangan mereka, tokohtokoh modernis seperti al-Afghani, Abduh, Rasyid Ridha, Sayyid Ahmad Khan, Muhammad Natsir dan Norcholish Madjid, tidak begitu populer. Mereka justru lebih tertarik pada pemikiran tokoh-tokoh seperti Hassan Hanafi, Muhammed Arkoun, Mahmud Muhammad Toha, Muhammad 'Abid al-Jabiri, Nasr Hamid Anu Zayd, Abdullah Ahmed al-Na'im dan sebagainya.

Memang, hampir secara luas diakui bahwa telah terjadi perkembangan yang cukup pesat dalam tradisi intelektual NU. Akan tetapi bagaimana bentuk dan identitasnya masih belum banyak yang mengkaji. Greg Barton, ketika mengkaji corak pemikiran Gus Dur, mengkategorikannya sebagai noe-modernis. ${ }^{7}$ Mengacu kepada konsep Fazlur Rahman, Greg Barton memandang corak pemikiran Gus Dur sebagai perpaduan antara semangat modernis dan khazanah klasik, walaupun Barton sendiri mengakui bahwa tema-tema pemikiran mereka merupakan kelanjutan dari apa yang telah dilakukan oleh kaum modernis sebelumnya.

Yang perlu diberi catatan di sini adalah bahwa corak pemikiran Gus Dur sama dan menjadi inspirasi bagi kalangan intelektual NU lainnya. Dengan demikian, kategori neo-modernisme juga dapat dilabelkan kepada mereka. Yang menjadi pertanyaan adalah benarkah tradisi intelektual baru di kalangan NU mempunyai pijakan modernisme Islam yang disentesiskan dengan khazanah klasiknya? Kalau benar, apa indikasi dan

\footnotetext{
${ }^{7}$ Ketegori neo-modernis oleh Barton diberikan kepada pemikiran empat tokoh yang dikajinya, yaitu Abdurrahman Wahid (Gus Dur), Nuscholish Madjid, Djohan Effendi, dan Ahmad Wahib. Keempat tokoh itu menurutnya mencoba mensentesiskan antara khazalah klasik dan semangat modernisme. Istilah neo-modernisme digunakan untuk menggambarkan posisi keempat tokoh tersebut dan membedakannya dengan tokohtokoh modernis sebelumnya. Komunitas neo-modernis ini mencoba menawarkan sebuah mendekatan baru pada konsep ijtihad, di mana pola pendekatan yang dikembangkan merupakan kelanjutan lebih jauh dari yang pernah dilakukan oleh para modernis sebelumnya dan sekaligus, khususnya bila dilihat dari gaya yang dikenal dalam tradisi belajar klasik, lebih aktual, lebih menantang serta lebih radikal. Dalam pemahaman seperti inilah istilah neo-modernisme mampu menggambarkan gerakan intelektual baru dan bertujuan untuk membedakan dari gerakan yang dikembangkan oleh kalangan tradisionalisme dan modernisme, meskipun sebenarnya neo-modernisme tersebut masih menyentuh ide-ide yang dikembangkan oleh gerakan kaum modernis sebelumnya. Selanjutnya lihat Greg Barton, Gagasan Islam Liberal di Indonesia: Pemikiran Neo-Modernisme Nuscholish Madjid, Djoban Effendi, Ahmad Wabib dan Abdurrahman Wabid, (Jakarta: Paramadina, 1999), hlm. 12.
} 
referensi yang dipakai oleh Barton? Sebab dalam kenyataanya, baik dalam ceramah dan tulisan-tulisannya, meraka jarang, atau bahkan tidak pernah, bereferensi kepada pemikiran tokoh-tokoh modernis.

Barton mungkin lupa bahwa gerakan modernisme dalam Islam mempunyai sejarah dan konteksnya sendiri. Garis geneologi pemikiran modernis, juga neo-modernis, bersambung kepada Wahabi dan berpuncak kepada Ibnu Taimiyah yang jelas-jelas mencerca tradisionalis. ${ }^{8}$ Di Indonesia, juga terjadi hal yang sama di mana dalam sejarahnya modernis mendiskreditkan keberadaan tradisionalis dan begitu sebaliknya. Dengan demikian, apapun produk pemikiran kalangan intelektual NU tidaklah relevan dikatakan mempunyai keterkaitan dengan modernis. Produk pemikiran mereka merupakan pilihan independen yang mencoba mengolah dan mentransformasikan khazanah tradisinya secara radikal dalam menjawab tuntutan riil masyarakat dan bangsanya, dan tidak mengacu kepada modernisme seperti yang dikatakan Barton.

\section{Islam Nusantara Versus Neo-Modernisme}

Bantahan terhadap pelebelan neo-modernisme kepada tradisi intelektualisme di Islam Nusantara didasarkan kepada beberapa argumen. ${ }^{9}$ Pertama, dari segi geneologi pemikiran dan pemahaman keagamaan, kalangan Islam Nusantara lebih menekankan kepada keberlanjutan tradisinya. Mereka justru mempunyai resistensi yang kuat terhadap gerakan modernis. Kalaupun muncul corak liberal dalam pemikiran mereka, tidak lebih dari upaya mentransformasikan dan meramu tradisinya dengan pemikiran yang lebih progresif, sehingga menjadi pemikiran yang berakar kepada tradisi secara kuat, tapi mempunyai jangkauan pemahaman yang luas.

Kedua, dari segi topik dan pilihan wacananya, terlihat adanya kegusaran terhadap fenomena gerakan simbolis dan formalisme Islam yang dinilainya tidak produktif bagi gerakan Islam. Sementara pada saat yang bersamaan, kalangan modernis justru mengusung isu formalisme Islam yang ingin dimasukkan pada kehidupan kenegaraan. Kalangan Islam Nusantara menempatkan agama sebagai sub-kultur di tengah kultur besar yang bernama bangsa. Islam dalam hal ini haruslah berada pada wilayah masyarakat dan menjadi roh bagi masyarakat dan bangsa ini

${ }^{8}$ Lihat Ahmad Baso, "Neo-Modernisme Islam vs Post-Tradisionalisme Islam" dalam Tashwirul Afkear Edisi No. 9 Tahun 2000, (Jakarta: Lakpesdam NU, 2000), hlm.

9 Selanjutnya lihat Muh Hanif Dhakiri dan Zaini Rahman, Post-Tradisionalisme Islam: Menyingkap Corak Pemikiran dan Gerakan PMII, (Jakarta: Isisindo Mediatama, 2000), hlm. $5-8$. 
tanpa harus dimasukkan ke dalam institusi negara. Dalam kehidupan bernegara, kalangan Islam Nusantara lebih memilih mengusung tematema demokrasi, pluralisme, civil society dan toleransi antar umat beragama.

Karena sikap resistensinya terhadap modernis, kalangan intelektual NU menolak untuk mengikuti sejak tahapan pemikiran modernis. Sebab, kalau itu terjadi berarti setiap kemajuan pemikirannya selalu berada di belakang dan mengekor secara linear kepada apa yang dicapai modernis. Oleh karena itu, munculnya corak pemikiran liberal di kalangan mereka merupakan kelanjutan dari transformasi tradisinya secara meloncat melampaui batas yang dicapai oleh moderinis. Hal itu terjadi karena wacana dan doktrin yang diusung oleh kaum modernis dinilai tidak produktif bagi lahirnya transformasi dan revolusi sosial komunitasnya. Istilah yang muncul kemudian adalah "Post-Tradisionalisme Islam". ${ }^{10}$

Istilah post-tradisionalisme islam merupakan produk pemikiran yang bebasis pada tradisi dan ditransformasikan secara meloncat; yakni pembentukan tradisi baru yang berakar pada tradisi miliknya, akan tatapi mempunyai jangkauan yang sangat jauh untuk memperoleh etos progresif dalam tranformasi dirinya. Yang dimaksud tradisi di sini adalah keseluruhan khazanah masa lalu yang hadir dalam dan bersama kehidupan kita. Tradisi mempunyai cakupan yang cukup luas. Ia meliputi yang bersifat maknawi (al-turâts al-maknawi) seperti pemikiran, yang berbentuk material (al-turâts al-mâdy) seperti norma dan kebudayaan, tradisi nasional kebangsaan (al-turâts al-qaumy) yang datang dari pendahulu kita, serta tradisi kemanusiaan pada umumnya (al-turâts al-insâny) yang kita terima dari khazanah masa lalu orang lain. ${ }^{11}$

Yang dilakukan kemudian adalah memposisikan rangkaian historis khazanah klasik sebagai produk pemahaman yang berdialektika dengan dimensi ruang dan waktu. ${ }^{12}$ Tradisi dalam konteks post-tradisionalisme Islam dipandang sebagai pendorong kemajuan apabila dikelola secara positif dan kreatif. Dengan tradisi, suatu masyarakat akan mampu membentuk cosmos (keteraturan dan ketertiban), dan tanpanya akan terjadi chaos (kekacauan) yang akhirnya membuat suatu masyarakat mengalami dis-orientasi.

\footnotetext{
10 Deliar Noer, Gerakan Islam Modern di Indonesia, (Jakarta: LPES, 2001), 199.

11 Muhammad 'Abid al-Jabiri, Al-Turâth wa al-Hadâthah: Dirâsat wa Munâqasyat, (Beirut: al-Markaz al-Tsaqafi al-'Araby, 1991), hlm. 45.

${ }^{12}$ Muh Hanif Dhakiri dan Zaini Rahman, Post-Tradisionalisme Islam., hlm. 9.
} 
Hal di atas berbeda dengan kalangan modernis yang sedari awal lahir untuk melawan tradisi yang dinilainya sebagai hambatan kemajuan. Padahal dengan menafikan tradisi, mereka justru gagap dalam merespon setiap perkembangan karena tidak mempunyai referensi kebudayaan. Akhirnya, kelompok ini menjadi tawanan tradisi baru tanpa bisa melakukan dialog atau tawar-menawar. Mereka ini tidak kalah fanatiknya dengan kalangan tradisionalis dalam menggenggam apa yang disebut sebagai modernisme itu sendiri. Akhirnya modernisme tidak dipahami secara substansial melainkan sebagai mitos. Modern bukan lagi merupakan etos berfikir dan sikap terhadap realitas melainkan sebagai identitas kelompok. Karena itu, modernisme lalu menjadi ideologi. ${ }^{13}$

Dalam pandangan post-tradisionalisme islam, bangunan pengetahuan dan pemikiran harus tetap mempunyai referensi kebudayaan atau tradisi. Sebab tidak ada pembaharuan tanpa tradisi, karena titik pangkalnya adalah tadisi. Menurut Hassan Hanafi, pembaharuan hanyalah rekonstruksi interpretasi terhadap tradisi sesuai dengan kebutuhan zaman. Dengan demikian, tradisi merupakan pijakan sekaligus "wasillah" menuju pembaharuan. ${ }^{14}$ Setiap tradisi, di samping menjadi pijakan, ia juga harus mempunyai jangkauan ke depan dalam rangka membangun tradisi baru yang berkelanjutan. Sebab, setiap generasi dapat membangun tradisinya sendiri sesuai dengan kebutuhan zamannya. Selanjutnya Hassan Hanafi mengatakan:

Tradisi tidaklah berdiri sendiri terlepas dari realitas yang hidup secara dinamis dan selalu berubah. Ia mengekspresikan semangat zaman, pembentuk generasi dan fase perkembangan sejarah. Dengan demikian, tradisi merupakan akumulasi interpretasi yang diberikan oleh setiap generasi sesuai dengan tuntutan zamannya, khususnya dasar pertama dari mana tradisi itu lahir memungkinkan terjadinya pluralisme, karena realitas adalah landasan terbentuknya tradisi. Begitu juga tradisi bukanlah sekumpulan keyakinan teoretis yang statis dan fakta-fakta yang mati, melainkan sekumpulan pengejawantahan teori-teori itu dalam situasi historis tertentu di mana suatu kelompok dapat mengungkapkan pikiran dan membentuk pandangannya terhadap alam. ${ }^{15}$

\footnotetext{
13 Abdul Mun'im Dz., "Pembaharuan Berbasis Tradisi”, sebuah pengantar dalam Muh Hanif Dhakiri dan Zaini Rahman, Post-Tradisionalisme Islam., hlm. Viii.

${ }^{14}$ Hassan Hanafi, Al-Turâth wa al-Tajdìd: Mauqifûna min al-Turâth al-Qadîm, (Beirut: alMuassasah al-Jâmi'iyyah li al-Dirâsat wa al-Nasr wa al-Tauzi', 1992), hlm. 13.

15 Komaruddin Hidayat, Menjadi Indonesia: 13 Abad Eksistensi Islam di Bumi Nusantara, (Jakarta: Mizan, 2004), 65.
} 
Pandangan di atas memberikan referensi bagaimana tradisi harus terus hidup, terpelihara serta dapat ditransformasikan dan di re-interpretasi sesuai dengan kebutuhan zamannya untuk membentuk tradisi baru. Prinsip ini juga berlaku dalam terbentuk dan berkembangnya pengetahuan. Pada konteks inilah post-tradisionalisme menemukan identitas dirinya di tengah percaturan dan perkembangan pemikiran. Ia mengambil keuntungan dari tadisi sebagai pijakan dalam melakukan pengembangan pengetahuan dan memberdayaan masyarakatnya. Di atas tradisi inilah post-tradisionalisme Islam menemukan fakta-fakta epistemologis dan merupakan produk aktivitas intelektual yang sifatnya socially determinated.

\section{Pos-tradisionalisme Islam Sebagai Kajian Aksiologis}

Lahirnya terma post-tradisionalisme Islam pada saat yang bersamaan merupakan produk dari praktek wacana. Sebagai wacana, produk pemikiran itu dapat lahir dan diekspresikan dalam bahasa dan ideologis keagamaan. Hal ini berarti memperkuat teori bahwa wacana sangat terkait dengan praktek-praktek ideologi yang diekspresikan dengan bahasa-bahasa ideologis pula. ${ }^{16}$ Pada gilirannya ia akan melibatkan praktek politik. Di sini dimensi politik tidak hanya menjadi alat produksi pengetahuan, tetapi juga senjata untuk memapankan pemikiran itu.

Fakta sejarah membuktikan bahwa suburnya perkembangan pemikiran Islam lahir dari konflik politik sejak masa khalifah Utsman bin Affan, lalu lahirlah beragam fiksi atau madzhab pemikiran yang lamakelamaan mengkristal mejadi ideologi dan aliran. Di tengah proses perkembangan itu, lalu yang terjadi adalah dialektika dan saling dominasi antara berbagai golongan pemikiran. Perdebatan antara Mu'tazilah dan Sunni misalnya, lebih dominan berada dan bergeser ke panggung politik dan kekuasaan dalam bentuk saling menyingkirkan dan mendominasi.

Pada masa khalifah al-Ma'mun sampai khalifah al-Mutawakkil (813847 M), Mu'tazilah secara represif dipaksakan menjadi madzhab resmi negara. Tak pelak lagi, paham abl al-hadìts dan tokoh-tokohnya ketika itu disingkirkan dengan cara represif. Al-Makmun yang beraliran dan dekat dengan tokoh-tokoh Mu'tazilah memulainya dengan membuat kebijakan mihnah, yakni menguji dan mengetes paham tokoh-tokoh abl al-hadìts (ortodoksi tekstual) agar mengikuti paham Mu'tazilah, sedang yang tidak mau ikut dianggap kafir sehingga harus dihukum, dibunuh, dipukuli

${ }^{16}$ Michel Pecheux, Language, Semantic and Ideology: Stating The Obvios (London: Macmillan, 1982), hlm. 21. 
ataupun di penjara. Salah satu tokoh yang terkena mihnah tersebut adalah imam Ahmad bin Hambal, ahli Hadits yang belakangan menjadi nisbat aliran (madzhab) fiqh Hanabilah. Materi pengujian waktu itu adalah agar semua umat Islam harus mengikuti paham bahwa al-Qur'an itu makhluk yang baru, dan bukan kalam Allah yang melekat pada dzat-Nya dengan sifat qadim-nya. ${ }^{17}$

Pada masa al-Mutawakkil yang paham keagamaannya salafi ortodok (paham abl al-hadits), paham Mu'tazilah sebagai madzhab resmi negara dihapuskan. Penghapusan itu dibarengi dengan kebijakan penyinggkiran dan pengikisan paham Mu'tazilah, baik di lingkungan pemerintahan maupun di seluruh kalangan umat di seluruh dunia Islam. Pada saat itu muncullah tokoh baru yang bernama Abu Hasan al-Asy'ari sebagai tokoh yang membangun madzhab pemikiran baru di bidang teologi (kemudian disebut sebagai madzhab ablussunnah waljamâ'ah/sunnî) sebagai antitesis terhadap Mu'tazilah. ${ }^{18}$ Al-Asy'ari sendiri sejak lahir selama 40 tahun dibesarkan oleh dan sebagai tokoh Mu'tazilah, sebelum akhirnya nyempal (jawa-red) dan mendebat guru yang sekaligus ayah tirinya, al-Jubba'i, sebagai tokoh Mu'tazilah ketika itu. ${ }^{19}$

Memasuki abad Modern ini, wacana dengan pola praktik perjuangan antar kelompok, ideologi maupun kelas dalam Islam tidak melulu antara aliran-aliran pemikiran yang terwariskan sejak masa awal sejarah Islam, tetapi juga antar beragam corak pemikiran dan penafsiran terhadap Islam. Hal ini antara lain dapat dilihat dalam polarisasi corak pemikiran modernis-tradisonalis yang mengemuka sejak al-Afghani, pemikiran

\footnotetext{
17 Ahmad Amin, Dhuba al-Islam, (Kairo: al-Nahdlah, 1964), hlm. 631.

18 Hegemoni dan dominasi Sunni semakin kuat setelah Tugril wafat $(1063 \mathrm{M})$. Penggantinya Alp Arselan (1063-1092 M) yang beraliran Sunni mengangkat perdana menteri yang tokoh Sunni, Nidzâm al-Mulk menggantikan Kunduri. Sejak itulah aliran Sunni terus mendominasi secara hegemonik melalui berbagai kebijakan. Di samping cara-cara refresif lainnya, perangkat yang paling efektif dipakai untuk mendominasi aliran pemikirannya adalah melalui institusi pendidikan yang bernama perguruan Nidzâmiyyah, yang tersebar di seluruh dunia Islam, dari batas timur sampai batas ujung Maghribi. Tokoh-tokoh yang paling dominan mewarnai perkembangan Nidzâmiyyah adalah Al-Juwaini dan al-Ghazali. Lihat Al-Tsahratsani, Kitab al-Milal wa al-Nihal, (Kairo: Dar al-Manar, 1951), hlm. 99. Perguruan Nidzâmiyyah sebagai institusi pendidikan tidak hanya memberantas dan menutup ruang paham Mu'tazilah dan Syi'ah di kalangan umat, tetapi juga aliran pemikiran filsafat yang oleh al-Ghazali dianggap sebagai pemikiran yang menyesatkan dan membuat umat Islam syirik. Lihat Majid Fakhri, A History of Islamic Philosophy, (London: Longman, 1983), hlm. 304. Institusi pendidikan inilah yang paling efektif dan meluas sebagai alat produksi pemikiran sekaligus menyingkirkan pemikiran lainnya.

${ }^{19}$ Lihat al-Tsahratsatani, Kitab al-Milal wa al-Nihal, (Kairo: Dar al-Manar, 1951), hlm. 71.
} 
ortodoksi-religius melawan sekularis, Islam inklusif melawan fundamentalis, tekstualis melawan liberalis, dan sebagainya. Praktek ini juga berlangsung melalui alat-alat kekuasaan, ideologi, institusi pendidikan, kepemilihan bahasa (istilah) dan sebagainya. Terhadap kasus ini, dapat diilustrasikan dalam dua contoh berikut.

Pertama; Kasus yang terjadi di Turkey Modern pada masa kekuasaan Mustafa Kemal (1924-1938 M) dengan arus pemikiran Islam sekulernya. Untuk memenagkan pertarungan trend pemikiran ini dengan kalangan agamawan ortodok (ulama salaf), Mustafa Kemal menggunakan kebijakan yang sangat hegemonik dan represif, baik melalui apparatus fisik maupun ideologis. Kebijakan yang ditempuh ketika itu antara lain dengan menghapus lembaga sultân, pendidikan yang dinasionalisasi dan di-sekulerkan, syari'ah diganti hukum sipil yang diadopsi dari barat sebagai hukum yang diunifikasi, nasionalisasi Turky agar tidak lagi terikat dengan dunia dan simbol Arab, dan sebagainya. Prakteks seperti ini berlangsung sedemikian lama, sampai akhirnya Mustafa Kemal jatuh karena perlawanan dan kebangkitan para ulama melalui partai politik yang memenangkan suara dalam pemilu tahun 1946. Dan sejak itu arus pemikiran Islam fundamentalis-ortodok bangkit dan mengembalikan posisinya di tingkat lembaga pemerintahan dan politik. ${ }^{20}$

Kedua; Kasus pertarungan antara Islam tradisionalis (selanjutnya menjadi post-tradisionalime) dan modernis di Indonesia yang tidak hanya berlangsung dalam tataran wacana tetapi juga pada wilayah politik dan kekuasaan. Proses untuk saling mendominasi tersebut sampai berkembang pada pengkelasan antara Islam kota yang borguis dan Islam desa yang agraris dan tingkat ekonomi bawah.

Post-tradisionalisme Islam, di samping sebagai counter dan kritik kepada modernisme, pada saat yang bersamaan ia juga melakukan kritik terhadap tradisinya sendiri. Karena itulah lahirnya pemikiran ini merupakan fenomena yang mernarik dan unik, yakni tradisionalis dengan corak yang sangat liberal. Untuk melihat corak yang liberal ini dapat dilihat pada tiga indikasi. ${ }^{21}$

Pertama, sebagai kelompok Islam tradisional yang berlatar belakang pendidikan pesantren, ia justru mencoba melepaskan diri dari kungkungan tradisi. Doktrin teologi sunni yang selama ini "tak tersentuh" bahkan diharamkan untuk sekedar "diusik", kembali

20 Stanford J. Shew dan Ezel Kural Shew, History of The Ottoman Empire and Modern Turkey (Cambredge: Cambredge University Press, 1971), hlm. 375.

${ }^{21}$ Muh Hanif Dhakiri dan Zaini Rahman, Post-Tradisionalisme Islam., hlm. 9. 
dipertanyakan. Kalangan post-tradisionalisme Islam lebih memilih wacana teologi pembangunan atau transformatif yang membawa Aswaja ke tataran yang lebih rasional dan empirik, dengan jargon yang cukup populer, yakni Aswaja sebagai manbâj al-fikr.

Indikator kedua adalah munculnya kesadaran untuk melepaskan beban sejarah. Dalam konteks ini Islam dipahami sebagai yang berdimensi historis dimana produk pemahaman masyarakat Islam terhadap ajarannya selalu berdialektika dengan dimensi ruang dan waktu. Produk pemahaman ulama terdahulu tidak lagi dibebankan untuk diterima dan dilaksanakan secara taken for granted oleh umat Islam saat ini. Selanjutnya adalah muncul indikator ketiga, yakni keharusan munculnya pola berpikir ke-Islaman yang bisa melepaskan ikatan harfiah teks.

Islam kultural sebagaimana banyak diintrodusir oleh komunitas pengusungnya menawarkan penyegaran bagai tradisionalisme Islam di satu sisi dan modernisme Islam pada sisi yang lain. Pada sayap tradisional misalkan muncul apa yang disebut sebagai post tradisionalisme Islam sementara pada sayap modernis muncul apa yang disebut sebagai post puritanisme Islam. Sebagai upaya revitalisasi Islam kultural juga menawarkan penyegaran dalam tradisi pembacaan sumber-sumber tekstual kehidupan umat Islam dengan merujuk pada berbagai pemikir yang merupakan persambungan dari post tradisionalisme Islam.

Sebagai masyarakat agama, umat Islam disebut sebagai masyarakat dengan peradaban teks (badarat al-nas). Yaitu suatu masyarakat yang struktur kehidupannya diletakkan di atas landasan teks (al-Qur'an, hadits, tafsir, kitab-kitab fiqh dan sebagainya). Dalam masyarakat semacam ini maka teks menjadi sentral dalam kehidupan. Dalam artian ini seluruh aktivitas masyarakat Islam mesti berangkat dari dan melalui serta berakhir pada teks. 


\section{Kesimpulan}

Ada dua persoalan dalam masyarakat dengan peradaban teks Islam Nusantara itu. Pertama, sikap dan cara pandang masyarakat terhadap pembacaan teks Islam Nusantara, Kedua, cara baca (sistem nalar) yang digunakan masyarakat yang bersangkutan terhadap teks sebagai bagian dari kekayaan tradisi (turâth) yang dimiliki. Dengan demikian salah satu persoalan krusial yang menentukan bagi kehidupan masyarakat Islam dewasa ini adalah bagaimana menyikapi tradisi (turâth) yang telah diwarisi dari generasi ke generasi sepanjang sejarah. Mengingat tradisi, sebagaimana dikatakan Hasan hanafi (1992: 15), merupakan khazanah kejiwaan manusia (al-makhzûn al-nafs), yang menjadi pedoman dan piranti dalam membentuk masyarakat. Implikasinya tradisi kemudian menjadi kitab suci yang harus dipedomani dalam perilaku kehidupan sehari-hari. Ada penghargaan, pembelaan bahkan "pemberhalaan" luar biasa terhadap tradisi melalui suatu proses sakralisasi pemikiran keagamaan (taqdîs al-afkâr al-diny). Sakralisasi ini berlaku bukan hanya bagi teks primer (al-Qur'an) dan Teks sekunder (al-Hadits), tetapi juga berlaku bagi teks-teks tersier (tafsir, fiqh dan sebagainya). Dalam hal ini tradisi kemudian berubah menjadi tradisionalisme. Kungkungan tradisionalisme kemudian tampak dalam cara baca tardisional. Sebagian umat Islam memang ingin mencoba beranjak dari tradisonalisme dengan semangat merujuk secara langsung kepada teks primer dan sekunder (rujû́ ila alQur'ân wa al-Sunnah) namun sakralisasi telah menjebak mereka ke dalam kungkungan skripturalisme yang cenderung fundamentalistik dan radikal.

Inilah tampaknya yang menjadi problem krusial lain dalam dunia Islam. Oleh karena itu Metode tradisional dalam menelaah tradisi (qirâ'ah turâthiyyah li al-turâth) tampaknya sudah harus dilampaui oleh umat Islam dengan mengambil cara baca kontemporer (al-qirâah al-muasirah). Dengan cara baca kontemporer inilah umat Islam bisa lebih produktif dalam mengembangkan wacana keislaman dan responsif terhadap tantangan dan perubahan sosial dan kultural. 


\section{Daftar Pustaka}

Abu Zaid, Nasr Hamid. Hermeneutika Inklusif. Jogykarta: Jaya Pustaka, 2001.

Amin, Ahmad. Dhuḅa al-Islâm. Kairo: al-Nahdlah, 1964.

Barton, Greg. Gagasan Islam Liberal di Indonesia: Pemikiran Neo-Modernisme Nuscholish Madjid, Djohan Effendi, Abmad Wabib dan Abdurrabman Wabid. Jakarta: Paramadina, 1999.

Baso, Ahmad. "Neo-Modernisme Islam vs Post-Tradisionalisme Islam" dalam Tashwirul Afkar Edisi No. 9 Tahun 2000. Jakarta: Lakpesdam NU, 2000.

Baso, Ahmad. Islam Nusantara; Ijtibad Jenius dan Ijma' Ulama’ Nusantara. Jakarta: Pustaka Afid, 2015.

Hanafi, Hassan. Al-Turâth wa al-Tajdìd: Manqifunna min al-Turâth al-Qadìm. Beirut: al-Muassasah al-Jâmi'iyyah li al-Dirâsat wa al-Nasr wa alTauzi', 1992.

Hidayat, Komaruddin. Menjadi Indonesia: 13 Abad Eksistensi Islam di Bumi Nusantara. Jakarta: Mizan, 2004.

Jabiri (al), Muhammad 'Abid. Al-Turâth wa al-Hadâthah: Dirâsat wa Munâqasyat. Beirut: al-Markaz al-Tsaqafi al-'Araby, 1991.

Muh Hanif dan Zaini Rahman. Post-Tradisionalisme Islam: Menyingkap Corak Pemikiran dan Gerakan PMII. Jakarta : Isisindo Mediatama, 2000.

Noer, Deliar. Gerakan Islam Modern di Indonesia. Jakarta: LPES, 2001.

Pecheux, Michel. Language, Semantic and Ideology: Stating The Obvios. London: Macmillan, 1982.

Schawts, Stephen. Moderatism vs Fundamentalisme. Jakarata: LibForAll, 2008.

Stanford J. Shew dan Ezel Kural Shew. History of The Ottoman Empire and Modern Turkey. Cambredge: Cambredge University Press, 1971.

Tsahratsatani. Kitab al-Milal wa al-Nihal. Kairo: Dar al-Manar, 1951.

Wahid, KH Abdurrahman. Mengurai Hubungan Agama dan Negara. Jakarta: Erlangga, 1999.

Zuhdi. Nasionalisme NU. Semarang: Aneka Ilmu, 2007. 